\title{
Municipal solid waste incineration bottom ash: Physicochemical characterization of organic matter
}

\author{
S. Dugenest, H. Casabianca and M.F. Grenier-Loustalot* \\ Service Central d'Analyse, Centre National de la Recherche Scientifique, USR 059, \\ BP. 22, 69390 Vernaison, France
}

\begin{abstract}
The aim of this work was to characterize the initial organic content of a selected municipal solid waste incineration (MSWI) bottom ash. This was realized by elemental carbon analysis using pyroanalysis of untreated samples. In addition, MSWI bottom ash extracts obtained by supercritical fluid extraction (SFE) or hot solvent extraction (Soxtec), were analyzed using gas chromatography (GC) coupled to either a mass spectrometry detector (MSD) or a microwave induced plasma atomic emission detector (MIP-AED). The results showed that the labile organic carbon fraction of the MSWI bottom ash is non-negligible (about $1400 \mu \mathrm{g} / \mathrm{g}$ ) and that it includes mainly carboxylic acids, $n$-alkanes, steroids and phthalates. The latter two families, as well as polyaromatic hydrocarbons that were also determined, would appear to confer a toxic character on MSWI bottom ash. In light of the well-designing and operating of the incineration facility, the results seem to be representative of a widespread quality of bottom ash.
\end{abstract}

Key words. MSWI bottom ash - organic matter - pyroanalysis - GC-MSD - GC-MIP-AED.

\section{Introduction}

In France, $37 \%$ of the municipal solid waste are eliminated by incineration with or without energy recovery [1]. Municipal solid waste incineration (MSWI) produces large quantities of bottom ash (2.7 Mt/year) which can be reused in public works in a few European countries [1].

Studies on the characterization of MSWI bottom ash have led to the chemical and mineral characterization of inorganic matter [2-4]. MSWI bottom ash is composed primarily of silica, metal oxides, silicates, chlorides and sulfates, but also contains non-negligible concentrations of heavy metals including $\mathrm{Zn}, \mathrm{Pb}, \mathrm{Cu}, \mathrm{Ni}, \mathrm{Cr}, \mathrm{Cd}$ [2]. In addition it contains small amounts of unburnt organic matter including maybe some organic trace pollutants which could be scattered in the environment if bottom ash is used as road building materials.

Consequently, the organic matter of MSWI bottom ash must be characterized. An analytical methodology was developed to identify and quantify organic compounds present, involving two extraction techniques, supercritical fluid extraction (SFE) and hot solvent extraction (Soxtec). As a result of the unique properties of the supercritical fluid (low viscosity, high coefficient of diffusion, low toxicity) [5-7], SFE can be used to extract a wide range of organic compounds including hydrocarbons, pesticides, polyaromatic hydrocarbons (PAH's), polychlorinated biphenyls (PCB's), from environmental (soil, sediment), agricultural (plants, animal fat) or industrial samples (fly ash) [8-13]. In spite of this, the technique has some limitations, in particular extrac- tion by pure carbon dioxide in the supercritical state is limited to the dissolution of apolar or slightly polar compounds [14]. A second technique was thus used to extract highly polar compounds, hot solvent extraction (Soxtec), better suited to these compounds. The Soxtec technique is more rapid, more reliable and more economical, and so it was preferred over the classical soxhlet method.

The extracts were analyzed by using two state of the art analytical tools: gas chromatography coupled to a mass spectrometry detector (GC-MSD) and gas chromatography with microwave induced plasma atomic emission detection (GC-MIP-AED). GC-MSD can rapidly identify different types of compounds as a result of the characteristics of the mass detector (sensitivity, universality) and the databases built into the system. In selected ion monitoring (SIM) mode, analyses are highly sensitive (detection limit about 0.5 pg) and specific, leading to the quantification of specific aromatic compounds such as PAH's [15] and steroids $[13,16,17]$. The MIP-AED is a specific and multi-element detector for GC. After calibration with a reference product, quantification of compounds with different chemical natures can be accomplished [18].

\section{Experimental section}

\section{MSWI bottom ash sampling}

The nature of MSWI bottom ash is closely linked to the nature of the solid waste, the type of incinerator and the 


\section{Original articles}

combustion conditions. We have selected one facility having an high incineration capacity and consequently producing high amounts of bottom ash.

The facility is located near an urban area. As a result of the french customs [1], municipal solid waste include papercardboard $(30 \%)$, fermentable matter $(25 \%)$, glass $(12 \%)$, fines $(10 \%)$, plastics $(10 \%)$, metal $(6 \%)$, textiles $(2 \%)$ and undefined materials (5\%) (mean composition). The nature and the volume of solid waste are relatively constant from day to day.

The incinerator is one of the most common type of MSWI system in use today. It has been operated since 1989 and its rated incineration capacity is $12 \mathrm{t} / \mathrm{h}$. Before combustion, solid waste are not preprocessed to remove materials including ferrous or non-ferrous metals and glass. They are fed into the combustion chamber via gravity and transported through the furnace via a system consisting of 6 rollers disposed on a slightly inclined plane. Inside the furnace, the air supply is controlled and the gas temperature reaches roughly $1200{ }^{\circ} \mathrm{C}$. In furnace exit, bottom ash is collected by an extractor using water to cool it. Then elements larger than $30 \mathrm{~mm}$ are separated and ferrous metal are magnetically recovered with an over-band. At last bottom ash is deposited in a pit.

The MSWI bottom ash sample was collected over a 7 day time period, in october. It reached about $400 \mathrm{t}$ distributed into 20 dumper-trucks. The initial sample $(500 \mathrm{~kg}$ ) was prepared by collecting 2 buckets from each truck. Its moisture content was $16.3 \%$ wt. It was composed of particles whose diameter reached from 0 to $30 \mathrm{~mm}$, and high amounts of unburnt paper, metal containers and glass weren't observed.
Several representative samples of MSWI bottom ash ( $80 \mathrm{~g}$ ) were prepared from the on-site initial sample by quartering, drying $\left(30{ }^{\circ} \mathrm{C}\right)$, grinding and sieving $(<4 \mathrm{~mm})$; the grinding residues (representing less than $0.5 \%$ in mass) were composed mainly of scrap iron which was excluded.

The samples of MSWI bottom ash were stored at $4{ }^{\circ} \mathrm{C}$.

\section{Sample processing}

Figure 1 illustrates the methodology for the physicochemical characterization of MSWI bottom ash. Because of the heterogeneous particle size distribution of the material $(<4 \mathrm{~mm})$, it is not possible to form a representative sample of about $5 \mathrm{~g}$ of a sample of MSWI bottom ash for the extraction of organic compounds. Reduction of sample particle size by fine grinding may cause structural modifications or losses (by heating) of organic compounds. Each sample was thus screened into six particle size classes, whose diameters were included in the interval indicated in $\mathrm{mm}$. A sample of about $5 \mathrm{~g}$ of classes 1 to 5 was then prepared by manual quartering. Fraction 6 was divided into two samples.

The seven samples were first extracted with supercritical carbon dioxide for $30 \mathrm{~min}$, using a Hewlett-Packard (HP) Model 7680 apparatus. With the conditions of pressure (318 bar) and temperature $\left(120{ }^{\circ} \mathrm{C}\right)$ chosen, the density of the supercritical fluid was relatively high $\left(0.61 \mathrm{~g} / \mathrm{cm}^{3}\right)$ and was thus able to solubilize efficiently different types of compounds [5,14]. This first extraction step yielded seven $1 \mathrm{~mL}$ extracts of double distilled hexane (SDS, HPLC grade).

The SFE residues of classes 1, 2 and 3 were mixed and then extracted with a Soxtec apparatus (Tecator) using $100 \mathrm{~mL}$ of methanol (Chromanorm, HPLC grade).

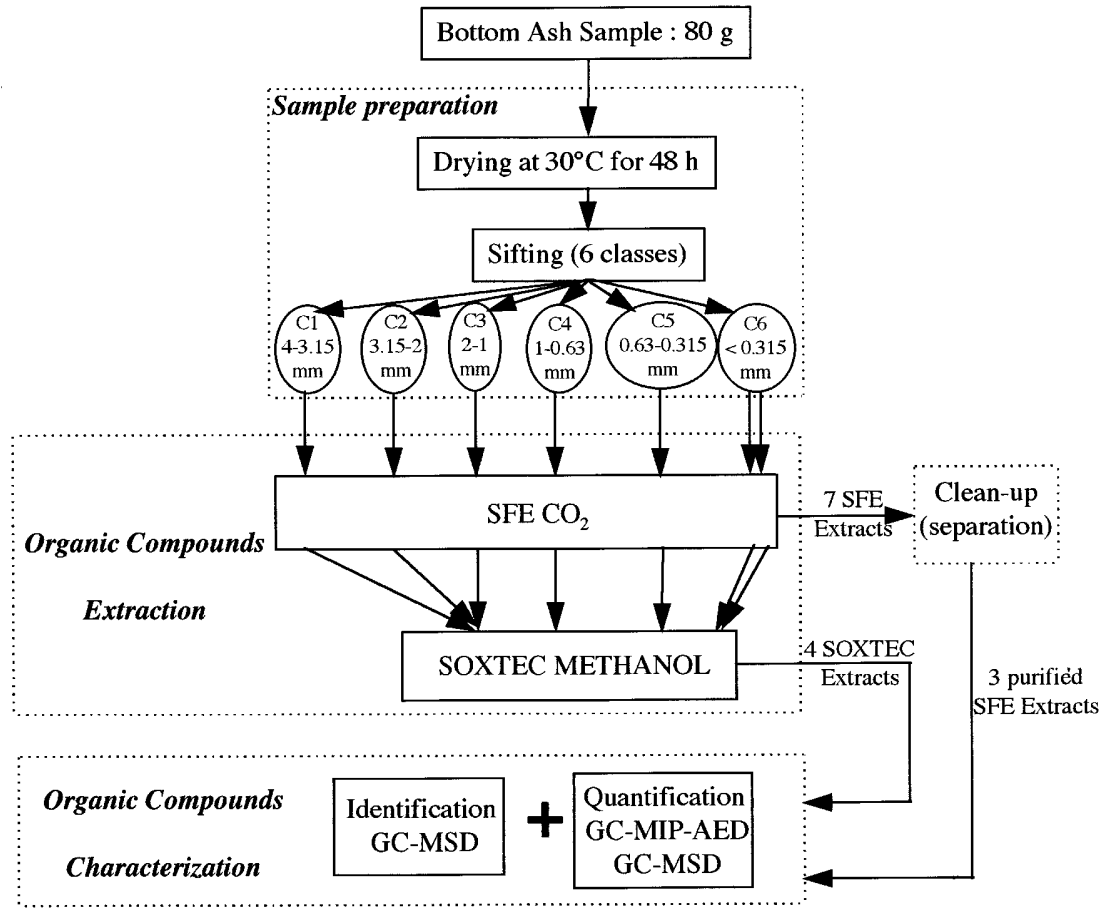

Fig. 1. Physicochemical characterization methodology of MSWI bottom ash. 
The two-step extraction first involved adding the sample to a cellulose cartridge (Whatman) and immersing it in boiling solvent for $2 \mathrm{~h}$. The cartridge was then raised above the surface of the solvent for a $1 \mathrm{~h}$ rinse of the sample by pure solvent dripping from the condenser. The SFE residues of classes 4 and 5 were extracted separately, using the Soxtec apparatus as above. The two class 6 SFE residues were pooled and extracted with the Soxtec. The second extraction step yielded four $1 \mathrm{~mL}$ methanol extracts.

The SFE extracts contained a large number of different types of compounds in variable concentrations as a result of the non-selective conditions adopted for extraction. In order to facilitate the determination of these compounds, the seven SFE extracts were pooled in a single fraction and submitted to a silica clean-up separation of compounds with different polarities. This procedure yielded three purified SFE extracts. The four Soxtec extracts containing primarily very polar compounds were analyzed directly. Each extract was analyzed by GC-MSD and GC-MIP-AED.

\section{Analysis methods}

\section{Elemental carbon analysis}

Elemental carbon analysis of the volatile and non-volatile fractions of MSWI bottom ash was conducted with an instrument which couples pyrolysis to temperature programming and elemental analysis by infrared absorption spectrophotometry. The apparatus was designed and built in the Service Central d'Analyse (European patent Nos. 269, 511 (1987), registered trademark Fractel ${ }^{\mathrm{TM}}$ ).

\section{Gas chromatography with mass spectrometry detection (GC-MSD) and microwave induced plasma atomic emission detection (GC-MIP-AED)}

Chromatographic separation was achieved on an HP Model 5890A Series II gas chromatograph (GC), equipped with a $30 \mathrm{~m} 5 \%$ phenyl (equivalent) polysilphenylene siloxane capillary column with a $0.22 \mathrm{~mm}$ i.d., and $0.25 \mu \mathrm{m}$ film thickness (BPX5, SGE). The instrument was equipped with an HP Model 7673A programmable automatic injector. The injector was maintained at $280{ }^{\circ} \mathrm{C}$ in splitless mode $(1 \mu \mathrm{L})$. After an initial plateau of $5 \mathrm{~min}$ at $60{ }^{\circ} \mathrm{C}$, oven temperature was increased at the rate of $10{ }^{\circ} \mathrm{C} / \mathrm{min}$ up to $315{ }^{\circ} \mathrm{C}$, followed by a 15 min plateau at that temperature. As the chromatographic conditions for the two couplings (GC-MSD and GC-MIP-AED) were identical, there was consistency of the measurements obtained with the two detection systems.

The GC-MSD coupling configuration was equipped with an HP Model 5972 Series MSD mass detector (electron impact, $70 \mathrm{eV}$ ). The transfer line was maintained at $280^{\circ} \mathrm{C}$. Qualitative analysis was conducted in scan mode that counts all ions in each peak. The mass interval scanned was from 40 to 450 a.m.u. at a rate of 1.8 scans/s.

The quantitative analysis of specific aromatic compounds (PAH's and steroids) was carried out in SIM mode with external standards, selecting ions characteristic of the target molecule. The fragments used for analysis of PAH's were the molecular ion of each compound. Seventeen PAH's were quantified after external calibration using a reference mixture (Interchim, M-8100-QC). Two to three characteristic ions were selected for the analysis of steroids (heavy compounds). Six compounds were quantified after external calibration with reference products (Touzart-Matignon or Sigma). In this case, the initial GC oven temperature was $150{ }^{\circ} \mathrm{C}$. In both cases, relative error of quantification was estimated at between 5 and $10 \%$.

GC-MIP-AED coupling involved an HP Model 5921A microwave induced plasma atomic emission detector. Compounds were quantified on the carbon emission line at $193 \mathrm{~nm}$ (very sensitive). Helium make-up flow rate was $60 \mathrm{~mL} / \mathrm{min}$. Inlet pressures of the make-up gas and reactant gases (oxygen and hydrogen) were $400 \mathrm{kPa}, 160 \mathrm{kPa}$ and $200 \mathrm{kPa}$, respectively. A nitrogen flow rate of $3 \mathrm{~L} / \mathrm{min}$ was maintained inside the spectrometer (purge). The transfer line temperature was maintained at $280{ }^{\circ} \mathrm{C}$. The microwave cavity was under a pressure of $10.3 \mathrm{kPa}$ and temperature was $280{ }^{\circ} \mathrm{C}$. The elemental response of the detector was calibrated with three reference products (Aldrich) widely used in the laboratory. The carbon detection limit calculated as 3 times the standard deviation of the noise was $0.1 \mathrm{ng}$. Relative error of quantification was estimated at about $10 \%$.

\section{Results and discussion}

\section{Determination of volatile and non-volatile fractions of carbon}

A sample of each particle size class was subjected to pyroanalysis. Volatile and non-volatile fractions of carbon (Fn) in each particle size class $(\mathrm{Cp})$ were quantified (Tab. I). Fractions F1 to F5 were defined for the corresponding pyrolysis temperature interval. Fractions F1 and F2 (sample under inert gas) contained labile carbon, including organic compounds whose boiling temperatures were lower than $650{ }^{\circ} \mathrm{C}$ [19]. Fraction F3 corresponded to heavy molecules (polymers), and fractions F4 and F5 (sample under oxygen enriched helium gas) contained non-volatile carbon in MSWI bottom ash and cokes formed during pyrolysis. Since the mass proportion of each particle size class was known, the carbon concentration of each fraction of the reconstituted sample $(<4 \mathrm{~mm})$ could be calculated.

Organic compounds are mainly contained in fine particles (< $0.315 \mathrm{~mm})$. Class 6 , however, accounted for only $15 \%$ (in mass) of the entire sample of MSWI bottom ash. Considering the mass distribution of particle classes in the sample, the quantities of F1 and F2 in classes 3, 4 and 5 were significant contributors to the total organic carbon concentration; the contribution of inorganic compounds such as carbonates and bicarbonates, to $\mathrm{F} 1$ and $\mathrm{F} 2$, was proved indeed to be negligeable. The carbon concentrations of F1 and F2 in classes 1 and 2 were less significant; large particles contained few organic compounds. 


\section{Original articles}

Table I. Quantification results ( $\mu$ g carbon/g dry matter) of volatile and non-volatile fractions of carbon (Fn with $n=1$ to 5) in the particle size classes ( $\mathrm{Cp}$ with $\mathrm{p}=1$ to 6 ). Relative standard deviation: 1 to $7 \%$.

\begin{tabular}{|c|c|c|c|c|c|c|}
\hline \multirow{2}{*}{$\begin{array}{l}\text { Particle } \\
\text { size classes } \\
(\mathrm{mm})\end{array}$} & \multicolumn{5}{|c|}{$\begin{array}{l}\text { Fractions of carbon } \\
\quad \text { lability }\end{array}$} & \multirow[b]{2}{*}{$\begin{array}{c}\sum F \\
80{ }^{\circ} \mathrm{C} / 800{ }^{\circ} \mathrm{C} \\
\left(\times 10^{4} \mu \mathrm{g} / \mathrm{g}\right)\end{array}$} \\
\hline & $\begin{array}{c}F 1 \\
80{ }^{\circ} \mathrm{C} / 260{ }^{\circ} \mathrm{C} \\
(\mu g / g)\end{array}$ & $\begin{array}{c}F 2 \\
260{ }^{\circ} \mathrm{C} / 365{ }^{\circ} \mathrm{C} \\
(\mu g / g)\end{array}$ & $\begin{array}{c}F 3 \\
365{ }^{\circ} \mathrm{C} / 520{ }^{\circ} \mathrm{C} \\
(\mu g / g)\end{array}$ & $\begin{array}{c}F 4 \\
300{ }^{\circ} \mathrm{C} / 660{ }^{\circ} \mathrm{C} \\
\left(\times 10^{4} \mu g / g\right)\end{array}$ & $\begin{array}{c}F 5 \\
660{ }^{\circ} \mathrm{C} / 800{ }^{\circ} \mathrm{C} \\
\left(\times 10^{4} \mu g / g\right)\end{array}$ & \\
\hline $1_{(9 \%)}^{(4-3.35)_{(9)}}$ & 65 & 186 & 634 & 0.11 & 2.14 & 2.34 \\
\hline $\begin{array}{r}2(3.35-2.36) \\
(20 \%)\end{array}$ & 88 & 175 & 375 & 0.17 & 0.12 & 0.36 \\
\hline $\begin{array}{l}3(2.36-1) \\
(32 \%)\end{array}$ & 397 & 1300 & 1200 & 0.57 & 0.22 & 1.08 \\
\hline $\begin{array}{r}4(1-0.63) \\
(11 \%)\end{array}$ & 446 & 1300 & 2600 & 1.08 & 0.88 & 2.40 \\
\hline $\begin{array}{r}5(0.63-0.315) \\
(13 \%)\end{array}$ & 351 & 1100 & 2500 & 1.09 & 0.85 & 2.34 \\
\hline $\begin{array}{r}6(<0.315) \\
(15 \%)\end{array}$ & 1600 & 2200 & 4860 & 2.77 & 2.06 & 4.95 \\
\hline $\begin{array}{l}\text { Reconstituted } \\
\text { sample }(<4) \\
(100 \%)\end{array}$ & 485 & 1084 & 1856 & 0.90 & 0.80 & 1.92 \\
\hline Ground sample & 425 & 970 & 2200 & 0.91 & 0.63 & 1.90 \\
\hline
\end{tabular}

The concentrations of each fraction of the sample $(<4 \mathrm{~mm}), \mathrm{F} 1$ to F5, calculated from the analysis of each particle size class, agree with those determined by analyzing an MSWI bottom ash sample which was mechanically ground and dried at $30{ }^{\circ} \mathrm{C}$ for $24 \mathrm{~h}$. This validates the previously determined distribution of carbon fractions in MSWI bottom ash. The MSWI bottom ash studied contained a nonnegligible fraction of labile organic carbon, about $1400 \mu \mathrm{g} / \mathrm{g}$ $(\mathrm{F} 1+\mathrm{F} 2)$, which would be interesting to characterize at the molecular level for assessing its toxicity and the incurred environmental risk.

\section{Characterization of organic compounds}

The methodology defined was applied to different samples of MSWI bottom ash. The mean extracted carbon concentration in three different samples was $320 \pm 5 \mu \mathrm{g} / \mathrm{g}$. The protocol developed enabled us to circumvent the problem of heterogeneity and variability of MSWI bottom ash samples. Qualitative and quantitative results obtained with four different samples of MSWI bottom ash led to the conclusion that the most widespread (in nature) families of organic compounds were present in the samples analyzed. In particular we were able to detect.

\section{Carboxylic acids}

GC-MSD analysis of extracts of MSWI bottom ash in scan mode revealed the presence of carboxylic acids in high concentrations in the third purification fraction of SFE extracts, as well as in the Soxtec extracts. The total acid concentration of MSWI bottom ash was calculated to be about $73 \mu \mathrm{g} / \mathrm{g}$ (relative standard deviation: 10\%). Compounds containing between 6 and 20 carbon atoms (in increments of 1), saturated or unsaturated, were identified. The acid concentration profile found in MSWI bottom ash (Fig. 2a) shows that there was a predominance of compounds containing an even number of carbon atoms, especially $\mathrm{C}_{16}$ and $\mathrm{C}_{18}$ (palmitic and oleic acids), and then, fatty acids with an even number of carbon atoms, from 4 to 18 , are the most widespread in nature [20]. The short chain acids, from 6 to 10 carbons, account for a much lower proportion of the total quantity of acids.

\section{$N$-alkanes}

The analysis (with the same method) of the first purification fraction of SFE extracts led to the identification of the $n$-alkanes series, including $12 \leq n \leq 36$. Overall, the chromatographic profile of this extract corresponded to the profile of $n$-alkanes extracted from MSWI bottom ash. 


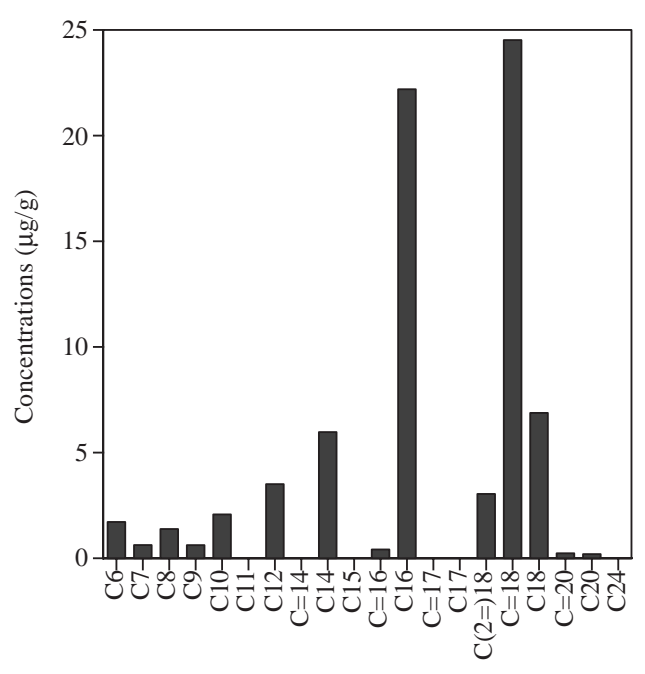

Number of carbon atoms and unsaturations

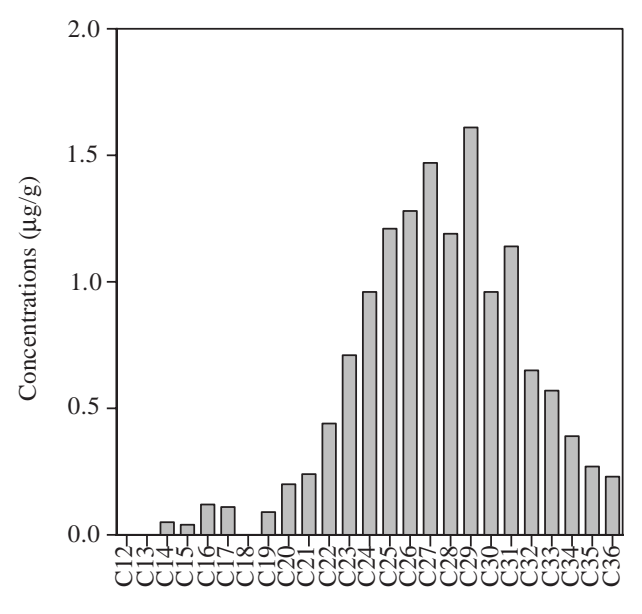

Number of carbon atoms

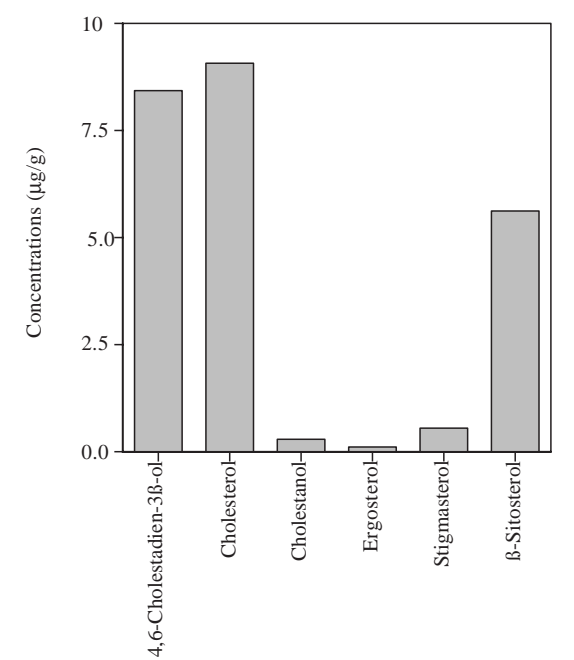

Fig. 2. Concentration profiles of a) carboxylic acids, b) $n$-alkanes, c) steroids.
Supercritical fluid extraction is the method of choice for extracting $n$-alkanes from MSWI bottom ash, since only several traces of these compounds were detected in the Soxtec extracts (negligible levels). The total concentration of $n$-alkanes in MSWI bottom ash was $14.1 \pm 1.6 \mu \mathrm{g} / \mathrm{g}$. The concentration profile of $n$-alkanes in MSWI bottom ash (Fig. 2b) shows a bimodal distribution with a short mode of $\mathrm{C}_{14}$ to $\mathrm{C}_{20}$ and a pseudo-normal distribution from $\mathrm{C}_{21}$ to $\mathrm{C}_{36}$. This profile presents some analogies with that of a petroleum paraffin series, such as heavy diesel fuel, whose distillation range is between $254{ }^{\circ} \mathrm{C}$ (b.p. of $\mathrm{C}_{14}$ ) to $496{ }^{\circ} \mathrm{C}$ (b.p. of $\mathrm{C}_{36}$ ). By analogy with oils [21], this profile could be characteristic of the degree of alteration (or ageing) of MSWI bottom ash.

\section{Other aliphatic compounds}

Unsaturated entities (alkenes) with 14 to 26 carbons in the alkyl chain were identified in parallel to saturated hydrocarbons. Few alcohols, aldehydes and ketones were detected (concentration ranges: 30 to $500 \mathrm{ng} / \mathrm{g}$ ). The compounds present contained an even number of carbons, primarily $\mathrm{C}_{16}$ and $\mathrm{C}_{18}$, while $\mathrm{C}_{12}$ and $\mathrm{C}_{14}$ alcohols were also characterized. $\mathrm{C}_{16}$ and $\mathrm{C}_{18}$ aliphatic hydrocarbons with a nitrile group (alkane nitriles) were also identified in MSWI bottom ash. Overall, these compounds contain the same number of carbon atoms and so their mutual occurence in the MSWI bottom ash are undoubtly linked. As an example, the alkane nitrile $\mathrm{Cn}$ may form from the transformation of the aldehyde $\mathrm{Cn}$ or the acid $\mathrm{Cn}$ in the presence of ammonia (or hydrogen cyanide), with the amide $\mathrm{Cn}$ as intermediate [22]. MSWI bottom ash also contains small quantities of alkyl esters (myristate, palmitate, or stearate) that were difficult to quantify because of the heterogeneity of the sample.

\section{Phthalates}

Seven phthalates were identified in extracts of crude MSWI bottom ash (about $6 \mu \mathrm{g} / \mathrm{g}$ ). Dibutyl phthalate and bis(2-ethyl-hexyl) phthalate were the major compounds. The concentrations of the other phthalates identified (dimethyl, diethyl, bis(2-methylpropyl), nonyloctyl, decyloctyl) were lower than $1 \mu \mathrm{g} / \mathrm{g}$. Used in industry as additives for polymers, these toxic compounds (especially the two majority species) are found in products from plastic (such as bottles, bags, etc.) degradation processes and are thus present in MSWI bottom ash. These compounds are also recognized as being relatively stable chemically and resistant to biodegradation, and so are in their original form in many degradation products.

\section{Steroids}

After GC-MSD analyses in SCAN mode, the third purification fraction of SFE and Soxtec extracts revealed the presence of relatively large concentrations of steroids with variable molecular weights. Six steroids of different origin were identified and quantified (Fig. 2c). Their total concentration was $24.1 \pm 0.2 \mu \mathrm{g} / \mathrm{g}$ and there were three major compounds: cholestadienol, cholesterol (both of animal origin) and 


\section{Original articles}

sitosterol (plant origin) [23]. Abundantly widespread in nature, the steroids present in MSWI bottom ash probably arose from plant or animal materials that weren't combusted. These compounds are considered as excellent biomarkers. Their transformations in the matrix could produce species representing a potential polluting source.

\section{Polyaromatic hydrocarbons}

PAH's are environmental pollutants because of their cancerogenic and mutagenic properties [8]. Their presence in the environment is due primarily to the incomplete combustion of wood, petroleum products, oils and coal [8]. PAH's are generated indeed when organic matter is treated in conditions of pyrolysis, i.e. incomplete combustion or combustion without oxygen, explaining their presence in MSWI bottom ash. The most commonly found types were identified in MSWI bottom ash (Tab. II), including phenanthrene (26.5\%), fluoranthene $(21.1 \%)$ and pyrene $(16.6 \%)$. Their total concentration varied from $130 \mathrm{ng} / \mathrm{g}$ to $210 \mathrm{ng} / \mathrm{g}$ (relative standard deviation: 5 to $10 \%$ ) from one sample to another and so their concentration in the MSWI bottom ash studied was relatively low.

\section{Other aromatic compounds}

The other aromatic compounds identified in extracts of MSWI bottom ash were primarily heterocyclic compounds containing oxygen, sulfur or nitrogen atoms, present in low concentrations (lower than $1 \mu \mathrm{g} / \mathrm{g}$ ) and so it was difficult to quantify them. However some of them are potentially toxic for the environment.

\section{Conclusion}

The analytical methodology developed has allowed to characterize the principal organic compounds in the organic matter extractable from MSWI bottom ash: carboxylic acids, $n$-alkanes, steroids and phthalates. The latter two families, as well as PAH's that were also determined, would appear to confer a toxic character on MSWI bottom ash. The environmental risk linked to MSWI bottom ash toxicity needs to be further evaluated.

The well-designing and operating of the facility is overall established. The results should be so characteristic of one quality of bottom ash which should be widespread in France.

We have shown that characterizing the organic matter, i.e. identifying and quantifying the different entities, in this type of complex matrix requires:

- the perfect understanding of particle size distribution and the physical state of the samples,

- the development of a very precise protocol for the extraction of the different organic compounds present,

- the use of different efficient detectors such as MSD and MIP-AED.
Table II. Quantification results (in relative proportions) of polyaromatic hydrocarbons.

\begin{tabular}{lc}
\hline PAH & Relative \\
\hline Naphthalene & 1.8 \\
Acenaphthylene & 1.7 \\
Acenaphthene & 0.9 \\
Fluorene & 5.6 \\
Phenanthrene & 26.5 \\
Anthracene & 4.2 \\
Fluoranthene & 21.1 \\
Pyrene & 16.6 \\
Benzo(a)anthracene & 3.8 \\
Chrysene & 8.4 \\
Benzo(a)pyrene & 4.7 \\
Benzo(k)fluoranthene & 1.8 \\
3-Methylcholanthrene & 0.2 \\
Dibenz(a,h)acridine & 0.9 \\
Indeno[1,2,3-cd] pyrene & 0.2 \\
Benzo(g,h,i)perylene & 1.6 \\
\hline
\end{tabular}

These results could be correlated with data from total assays of organic carbon, illustrating the effectiveness of the analytical methodology used in this work.

\section{Acknowledgments}

This study was conducted in the context of a thesis financed by the SITA group, 94 rue de Provence, BP. 693-09, 75425 Paris Cedex 09, France, whom we thank for their confidence and support.

\section{References}

1. Dugenest, S. Thesis (and references cited), Université Claude Bernard de Lyon, Dec. 1997.

2. "An international perspective on caracterisation and management of residues from solid waste incineration"; Summary Report of the International Ash Working Group, 1994.

3. Kirby, C.; Rimstidt, J. D. Environ. Sci. Technol. 1993, 27, 652.

4. Ollivier, J.; Pascual, C.; Sperber, J.; Le Cloirec, P. TSM 1995, $9,667$.

5. Guinamant, J. L. Analusis 1992, 20(1), 36.

6. Cross, R. F.; Ezzell, J. L.; Porter, N. L.; Richter, B. E. Int. Lab. 1994, 23.

7. Richards, M.; Campbell, R.M. $L C-G C$ 1990, 9(5), 358.

8. Dean, J. R. Analyst 1996, 121, 85R.

9. Myer, L.; Damian, J.; Liescheski, P.; Tehrani J. Spectra 2000 1992, 165, 57.

10. Miao, Z.; Zhang, Z.; Pawtiszyn, J. J. Microcol. Sep. 1994, 6, 459.

11. Friedrich, K.; Cammann, K.; Kleiböhmer, W. Fresenius J. Anal. Chem. 1995, 352, 730. 
12. Liu, Y.; Lopez-Avila, V.; Alcaraz, M.; Beckert, W. F.; Heithmar E. M. J. Chromatogr. Sci. 1993, 31, 310.

13. Magard, M. A.; Berg, H. E. B. J. Agric. Food Chem. 1995, 43, 114.

14. Engelhardt, H.; Gross, A. Trends Anal. Chem. 1991, 10(2), 64.

15. Chee, K. K.; Wong, M. K.; Lee, H. K. J. Chromatogr. A. 1996, 723, 259.

16. Aguilera, R. Thesis, Université Claude Bernard de Lyon, Jan. 1996.

17. Fattore, E.; Benfenati, E.; Marelli, R.; Cools, E.; Fanelli, R. Chemosphere 1996, 33(12), 2383.
18. Elbast, W. Thesis, Université Claude Bernard-Faculté de pharmacie. Institut des sciences pharmaceutiques et biologiques de Lyon, Nov. 1997.

19. Fixari, B.; Le Perchec, P.; Bigois, M. Fuel 1990, 69, 851.

20. Arnaud, P. Cours de chimie organique; 16th ed.; Dunod: Paris, 1996.

21. Rivet, L. Analusis 1995, 23(8), 378.

22. March, J. Advanced organic chemistry. Reactions, Mechanisms and Structure; 4th ed.; Wiley-Interscience: New York, 1992.

23. Chosson, P.; Lanau, C.; Connan, J.; Dessort D. Nature 1991, 351,640 . 